Published in: World Futures. The Journal of general Evolution, 48(1-4): 23-56, 1997.

\title{
The Physics of Collective Consciousness
}

\author{
by Attila Grandpierre
}

Attila Grandpierre, Ph.D. Konkoly Observatory of the Hungarian Academy of Sciences H-1525 Budapest P. O. Box 67., Hungary

February 6, 1996 


\section{Contents}

Abstract 2

Introduction 3

The Evolution of Consciousness 3

Collective Biological Fields 6

Physical Conditions of Consciousness $\quad 7$

The Levels of the Mind 8

Quantum-Vacuum Interactions in the Brain 10

Applications to Human and Cellular Brains $\quad 12$

Coupling Between Global and Local Brains 13

Frequencies of Interaction Between Different Brains 14

Quantum Energy Transfer Between the Brain and the Material Carriers of Thought 14

Quantum-Vacuum Interaction in the Universe 15

$\begin{array}{ll}\text { Spontaneous Targeting } & 17\end{array}$

Global Organisation and Action-in-Distance 18

The Fundamental Problem of Electromagnetism and Quantum Physics 19

$\begin{array}{ll}\text { The Source of the EM Field } & 21\end{array}$

Collective EM Field of the Biosphere $\quad 21$

Collective EM Field of Human Subjects 23

The Physics of the Evolution of Consciousness 25

Origin of Consciousness and its Relation to Emotional States 26

The Common Field of Consciousness $\quad 27$

On the Destination of the Universe 30

The Deformation of Consciousness in the Western Civilisation 31

Super-Organisms and Planetary Consciousness 31

Healing of the Collective Consciousness Field of Mankind 32

References $\quad 35$ 


\title{
The Physics of Collective Consciousness
}

\author{
ATTILA GRANDPIERRE
}

Konkoly Observatory, H-1525 Budapest, P. O. Box 67, HUNGARY, E-mail: grandp@ogyalla.konkoly.hu

ABSTRACT: It is pointed out that the organisation of an organism necessarily involves fields which are the only means to make an approximately simultaneous tuning of the different subsystems of the organism-as-a-whole. Nature uses the olfactory fields, the acoustic fields, the electromagnetic fields and quantumvacuum fields. Fields with their ability to comprehend the whole organism are the natural basis of a global interaction between organisms and of collective consciousness. Evidences are presented that electromagnetic potential fields mediate the collective field of consciousness. This result offers for the first time experimental access to the study of collective consciousness by measuring the field-related information-carrying potentials and their derivatives, the electric and magnetic fields between different individuals. The electrodynamic interaction of different brains/minds generates induction and in this way excitement, enhancement in the baseline of the interacting brains' activity. A list of empirical evidences is presented here proving the existence of this 'interactive excitement' effect in the known phenomenon of collective consciousness. The fundamental phenomenon of the collective consciousness is known as 'social facilitation' or 'group effect'. The character and completion of consciousness are outlined in the frame of this picture, and the role of the 'group effect' or 'social facilitation' as a primary factor in developing consciousness is described. A quantum-physical model of a multi-layered consciousness is presented, where the layering is expressed by the subsequent subtlety of the masses of the material carriers of information. I show that as the mental levels get deeper and more sensitive the couplings are on more and more global scales of their environment. I point out that direct, immediate action in distance actually exists in the electromagnetic field, which is the coupling, mediator field between waves and particles. I show how the environmental, natural and cosmic fields are determinative sources of our consciousness. The results presented point out that the Collective Field of Consciousness is a significant physical factor of the biosphere. I show that the morphogenetic field has an electromagnetic (EM) nature. EM fields are vacuum fields. Different basic forms of vacuum fields exist, and all kinds of fields, including the particle-mediated fields as well, when overlapping each other, seem to be in a direct resonant coupling, and form a complex, merged biofield. The vacuum model of consciousness presented here points to the inductive generation of consciousness, and to its self-initiating nature. Individual and collective 
methods, as well as the experimental possibilities of a global healing and improving the consciousness field of mankind are suggested.

KEYWORDS: olfactory, acoustic, electromagnetic, vacuum fields, generation of consciousness, evolution of collective consciousness, social evolution, completion of consciousness, healing

\section{Introduction}

It is generally accepted that consciousness evolved parallel to the biological and social complexity of the living systems. This observation suggests that the basic nature of consciousness is related to collective influences, and therefore consciousness is 'per se' a collective phenomenon. Endre K. Grandpierre (1996) in his essay "Cosmic Systems of Consciousness, Their Development, Two Principal Branches and Evolution from the Golden Age until the Present" has shown that consciousness is the manifestation of interactions. Ervin Laszlo (1995) has shown that a holographic information field is responsible for the physical, biological and paranormal phenomena. This holographic field is actually a non-linear vacuum field. The information field in biology is termed as biological or morphogenetic field and it appears in society as a collective field. Unfortunately, the presence and nature of social fields have not been explored yet to a degree when it is clear how they are related to the biological fields. If the nature of consciousness is based on elementary interactions, as suggested by Endre K. Grandpierre (1996), then we have to explore whether the interactions of known physical fields may serve as mediators of consciousness and may produce the fundamental phenomena of consciousness, the 'group effect'.

\section{The Evolution of Consciousness}

It is widely believed, that the way evolution manifest is from parts to the whole, from the inorganic matter through the unicellular organism towards the multicellular ones until the appearance of consciousness. This process is accompanied by a growing degree of complexity. This direction of the evolution of consciousness is naturally extrapolated towards the appearance of collective consciousness and the Consciousness Field of Mankind (Grandpierre, A., 1995). But why complexity is a necessary condition of a higher form of consciousness? I suggest a plausible answer: because the sensitivity to any stimulus may be increased through the interconnectedness of the constituents of the organism. The increased degree of sensitivity in groups is available through the interactive creation of collective states having energetic states with smaller net energy 
differences between each other than within the constituents themselves. Therefore they may interact with more subtle stimuli. According to my theory, this basic phenomenon works effectively when the energetic states of the constituents are close to each other. The maximal sensitivity of a system consisting of a fixed number of elements may be reached when the system builds up from almost identical constituents. Examples of this 'collective effect' are multicellular organisms, societies of insects, animals, and humans, and celestial bodies. The Earth, the Sun, the stars, and the galaxies are also systems consisting of similar components. Their organic nature has not been revealed in a scientific context, but now the new research shows that planets and stars do show fundamental lifephenomena and signs of sensitive interconnectedness (Grandpierre, A. 1996a, b, c, d). Regarding the large number of their constituents, the degree of attainable consciousness of these cosmic systems has to be enormously larger than that of humans. As Endre K. Grandpierre (1996a, b) showed, the evolution of the consciousness of cosmic systems divides into a cosmic and a biological branch.

This chain of thought places collective phenomena into the centre of evolution and the generation of consciousness. Our argumentation is substantiated by wide-range observations, e.g. that of L. Thomas (1974): "A solitary ant, afield, cannot be considered to have much of anything on his mind; indeed, with only a few neurones strung together by fibres, he can't be imagined to have a mind at all, much less a thought. He is more like a ganglion on legs. Four ants together, or ten, encircling a dead moth on a path, begin to look more like an idea. They fumble and shove, gradually moving the food toward the Hill, but as though by blind chance. It is only when you watch the dense mass of thousands of ants, crowded together around the Hill, blackening the ground, that you begin to see the whole beast, and now you observe it thinking., planning, calculating. It is an intelligence, a kind of live computer, with crawling bits for its wits." On the other hand, the 'group effect', a phenomenon of psychology which I suggest has a fundamental significance, arises in the same circumstances. Ants work three times more effectively if nearby co-working ants are present (Chen, 1937). Not only the presence of co-working partners, but also, the mere presence of passive 'observers' facilitates their activity (Dashiell, 1930). 'Social facilitation' is a general phenomenon accompanied by an enhanced level of brain activity appearing in the whole range of social animals, including humans as well (Triplett, 1898; see a review of the phenomenon in Atkinson et al., 1993).

To establish the proper context and assess the significance of the phenomenon, I gathered here a whole list of collective consciousness effects. Allport (1961) noted, that among developing children, the sense of other humans develops much earlier than the sense of self-identity. I suggest that this 'social primacy' is related to the frequently observed "emotional fertilisation" in kindergartens. Children cry and laugh even if they do not have any motive except that in their close environment somebody else acts in the same way. The phenomenon of "noise-ecstasy" usually appears among adolescent people, in classrooms. "In the age of adolescence whole classrooms become involved in the 
'mass state', which is a state which developing through mutual emotional infection. On these occasions the whole classroom become crazy, they make incredible noises, dance wild dances, rhythmically move, or simply produce a wild chaos. Every pupil participates in the orgy of the upheaval, even those ones, who are not inclined to behave that way within normal conditions and who immediately after the event regret having acted so" (Clauss, Hiebsch, 1964 ). Kurt Tepperwein notes that hypnosis becomes more effective if it is applied in groups, as a consequence of "spiritual infection" and imitation of the others (Tepperwein, 1977). The increase in the number of already hypnotised people facilitates the hypnosis of the next one. This phenomenon suggests the existence of a collective field. Large number of people (tens of thousands of people) were involved in epidemics of psychoses on several occasions and for long times (years) (Farkaslaki, 1939) in the medieval age. Similar occasions took place in the modern era, such as tarantism, demonopathy, dancing mania, mass hysteria (Smelser, 1962), mental epidemics, 'mass psychogenic illnesses' (see the recent review of Bartholomew, 1994). The transference of the anomalous behaviour was described as when the number of people showing the anomalous behaviour reached a certain threshold, the behaviour spread much more easily (Turner and Killian, 1972; Miller, 1985). The "Reutler-effect" shows that the contraction of the muscles of a person may enhance the contraction of the muscles of another person from a distance (Reutler, 1928). Stefán Figar (1959) showed that bodily changes related to special mental activities may easily be transferred to other people independently of their knowledge about each others' actions.

I have to point out, that all of these phenomena may be interpreted by an electromagnetic field model of consciousness, including the phenomenon of hypnosis. If consciousness is organised with the help of the EM field, this EM field may be able to transcend the borders of the organism emitting the waves (see the evidences later on), and interact with the consciousness field of another person nearby. This possibility is allowed by the measurements of Ravitz (1962), who showed that EEG changing during hypnosis presents a waking state pattern. Collective consciousness fields are suggested to act in the ancient Japanese NOtheatre and in the truly cathartic theatre performances (Vekerdy, 1974). As Vekerdy formulates, the artist may exert an effect on the audience in three ways: using words, through hearing, by movements, through seeing, and using intense emotions, which exert their effects through telepathy, extra sensory perception. In an experiment conducted by Charles Tart, two graduate students were mutually hypnotising each other. He had Anne hypnotise Bill and after he was hypnotised, he had Bill hypnotise her in return. Anne and Bill in this state experienced the same fantastic, hallucinated reality (Tart, 1969). Richardson (1995) experienced that an imaginary playmate, observed independently and consequently by nine children, was also observed by one adolescent male and also perceived by herself, the teacher personally, as a real 4-year old person. Richardson writes 'In my own case, during the contact, I was not aware of suspecting that she was an apparition until I had the thought "She does not belong in our yard and she is not 
even dressed right for this century." At that moment we made eye contact and she vanished, dropping the baseball cap.' We may observe that consciousness is fundamentally related to (external and internal) collective, or social interactions, and is elicited through enhanced emotional levels. The collective consciousness field effect is especially amplified when a large number of participants are involved. Therefore, the collective consciousness field of mankind may not only be influenced by nature but also by a modification of social origin, e.g. when significant amount of people are involved in mutual hypnosis. Psychological researches have shown that creativity is triggered in intense emotional states. The hypothesis that the determining factor of consciousness is related to emotional states is developed, considered and evidenced later on.

\section{Collective Biological Fields}

Experiments show that collective biological fields may dominate the individual field (Popp, 1994). The nature of the biological fields has not been understood, although it is clear that they are related to electromagnetic fields (Bauer, E., 1920; Gurwitsch, who worked at E. Bauer's institute, 1922; again an assistant of E. Bauer, Koltsov, 1936; Spemann, 1938; Weiss, P., 1939; Burr, 1956; Ravitz, 1962; Sheldrake, 1981, 1988; Popp et al., 1989; Bischof, 1995). Recently, H. Oldfield's life-long work substantiated that the biological field is mostly of electromagnetic nature, and postulated the hypothesis of a purely electromagnetic (in the followings EM) morphogenetic radiation (Oldfield, Coghill, 1988). Two other basic books on bioelectromagnetism are the ones by Becker and Selden (1985) and Smith and Best (1989).

I have to point to a yet unnoticed circumstance regarding the nature of the morphogenetic fields. If constituents of a group interact through electromagnetic fields, they have to be able to detect EM information coming from their environment, and also to be able to emit EM signs carrying information about their internal states. In that case they have to be EM antennas, receiving and broadcasting EM waves. But we know, that antennas are specially designed to be sensitive to a certain wavelength of EM radiation, and that the characteristics of the EM spectrum, as well as their receptive characteristics, depend on their sizes, and in general, on their geometrical forms. Interactive elements of a group, when using EM waves, are sensitive to each other's geometry, i.e. forms. It is easy to see that organic EM antennas regulated by the interchanged EM signs may be described as influenced by their 'morpho-genetic' field, i.e. any EM field acts as a morphogenetic field. This theory seems to be able to interpret e.g. the fact that the shape of the smelled molecule determines its information content (Thomas, 1974). If atoms are arranged in precisely the same configuration, by whatever chemical name, the compound molecule might smell as sweet. 
What is the function of the biological fields? In every cells hundreds of thousands of reactions set up every second. Most of the reactions of the cells have a substantial life-function, therefore they cannot happen by chance, but need specific guidance, timing and regulation, as they fulfil a function for the cell as a whole. Their regulation need a much quicker regulative system than the time scale of their reactions, since it requires an overview of the actual states and possibilities and the basic needs, and the co-ordination of the different factors. The regulative mechanism of the cell therefore has to work with subtle energies. The regulative system has to proceed the relevant informations in due time. Therefore, it has to work with the most effective information carriers, i.e. waves. The regulative mechanism of the organisms has to apply ultrafast interaction in order to be able to inform and co-ordinate the different reactions of the organism approximately simultaneously.

\section{Physical Conditions of Consciousness}

The physical means of information exchange between an organism and its environment is determined by the physical conditions, the size of the organism, and the biological time-scales. The regulation of the reactions with biological functions require processes faster and subtler than the reactions themselves. Acoustic waves propagate with a velocity of $v=1.4 \mathrm{~km} / \mathrm{s}$ in the human body. Taking a characteristic size of the human body $l=2$ metres, we can calculate a value for the characteristic acoustic frequency of the human body:

$\mathrm{f}_{\mathrm{ac}, \text { human body }}=v / l=10^{3} \mathrm{~Hz}$,

therefore the characteristic time scale of these acoustic waves is

$\mathrm{t}_{\mathrm{ac}, \text { human body }}=10^{-3} \mathrm{~s}$.

Using electromagnetic waves, the human organism has another characteristic frequency and time-scale, with $l=2 \mathrm{~m}$,

$\mathrm{f}_{\mathrm{EM}, \text { human body }}=10^{8} \mathrm{~Hz}=100 \mathrm{MHz}$,

$\mathrm{t}_{\mathrm{EM}}$, human body $=10^{-8} \mathrm{~s}$.

Larger frequencies belong to smaller wavelengths, therefore to inner signs, smaller frequencies mediate information from the environment. EM waves originate from the body, as well. Brains emit EEG waves between 1-40 Hz, in the range of the EM waves of the Earth, the Schumann waves (Schumann and König, 1954). The frequencies of the Earth's EM waves can be calculated using $L=40$ $000 \mathrm{~km}$, as

$f_{\mathrm{EM}, \text { Earth }}=300000 \mathrm{~km} / \mathrm{s} / 40000 \mathrm{~km}=7.5 \mathrm{~Hz}$.

The researches of Ludwig (1984) showed that Schumann waves are necessary as biotropic stimuli for the living organisms. Tsuvayev (see Merkulov, 1978) showed that the growth and development of mushrooms and water-plants ceases when isolated from environmental magnetic field. It is interesting that the acoustic resonant frequency of the human body falls into the range of 7-8 Hz. The 
human body is extremely sensitive to signs at this acoustic frequency. Noises with this frequency, if they are intense enough, may sensitively alter bodily functions. It seems to be strange that the resonant frequency is not the one determined on the basis of purely acoustic conditions. The coincidence of the acoustic resonant frequency with the EM frequency of the Earth and the EEG alpha-waves may suggest the close resonant coupling of these fields of different nature. It is another interesting coincidence, that the surface of the Earth also appears to have mechanical (acoustic) vibrations within the $10 \mathrm{~Hz}$ bands.

Schumann waves penetrate through the body to approx. $94 \%$, and are absorbed in approx. $6 \%$ at the specific frequencies the organism can resonate (Ludwig, 1984). It means that the source of the brain's activity may be triggered from outside the body. One part of the EM spectrum ( $f<100 \mathrm{MHz}$ ) is the outer, natural and cosmic source of our consciousness, the other part, with $f>100 \mathrm{MHz}$, is the inner source of our consciousness. Regarding the fact that the smaller frequencies, i.e. larger wavelengths are related to EM quanta of smaller, subtler energies, we obtain a result that the more subtle levels of the organisms' regulation belong to a hierarchy of global consciousness, to natural and cosmic sources of consciousness. In this context, it is interesting that the frequencies and time-development of the Schumann and EEG waves are similar (König, Angermüller, 1960).

The more subtle level behind the EM one is the level of quantum-vacuum interactions (QVI). Laszlo (1995) proposed that QVI may offer the solutions for the present problems of cosmology, biology, psychology and parapsychology. I worked out a quantitative model which shows the relationship between the different levels of our environment and the progressively deeper mental levels existing within us (Grandpierre, 1995a, b).

It is pointed out that the deeper mental levels (Grandpierre, 1995a), on which the 'aware consciousness' builds up, have larger capacity, are faster, therefore they require more subtle material carriers beyond the molecular and neural units, reaching the quantum range. Assuming a finite energy exchange between the vacuum field and the brain within the bounds of the uncertainty principle, a relation is found between the physical size of the brain and its relevant time scales. Using the time scales for information processing within the brain as a whole and within its cells, the characteristic frequencies of the electromagnetic and vacuum waves are obtained in the visible and the ultraviolet spectral ranges. It is pointed out that the formula derived for the couplings between the different mind levels gives values for the frequencies between the Universe and Man which are physically possible and actually plausible.

\section{The Levels of the Mind}


The $4 * 10^{10}$ neurones of the brain, having $10^{3}$ synapses, respectively, each of which has $10^{2}$ levels of "strength", would give us a mental "universe" consisting of maximum $10^{15}$ elements. This number is too small even if we consider the classic von Neumann estimate of $10^{20}$ bits as conscious information obtained during a lifetime. Taking into account that the amount of information reaching us from our environment through our external senses is estimated to be around $10^{9}-10^{10} \mathrm{bits} / \mathrm{sec}$ (see later on), this neuronal model becomes insufficient within $10^{6} \mathrm{sec}$, i.e. within 10 days, even if we count only the information coming from the environment. We can use a finite state model of the brain, but we definitely need much more states than the neural model can provide. The phenomenon of creativity gives an even more stringent constraint on the number of states of the brain (Grandpierre, 1995a).

The simple, exclusively neural model of consciousness is also counterindicated by some basic observations, e.g. the spontaneous excitation of neurones, when their activity potential develops spontaneously, i.e. not from the sensorial input. It means that an underlying mechanism exists on which the brain activity is organised. Already Szent-Györgyi drew attention to the need of submolecular biology and the role of spontaneous electron transfer in the cell's life activity (Szent-Györgyi, 1968). He pointed out that cell division may be regulated by donor-acceptor interactions, processes in which electrons go spontaneously from one molecule to another. Evidences were given that the electrons are moved by the energy of light from one molecule to another (Szent-Györgyi, 1968). He remarked, that electrons are necessary also in regulating the organism as a whole, and as a physical carrier of thinking since there is a basic need for a fast enough process, much faster than the biomolecules can be (Szent-Györgyi, 1974). This essay here was inspired by his lecture, trying to apply and extend it. Recently Ladik defended Szent-Györgyi's views on the proteins as good electrical conductors by numerical quantum-chemical calculations. Free electrons are present within proteins and they are substantial in DNA-protein interaction, therefore in the genetic regulation, in rapid signal transfer within biopolymers, and they play an important role in the self-regulation of the cell (Ladik, 1987, and more references therein). A new branch of science grew from the ideas of SzentGyörgyi, bioelectromagnetism. There is a tremendous literature studying the ultraweak electromagnetic radiation from cells, the biophotons (Popp, $\mathrm{Li}$ and $\mathrm{Gu}$, 1992; Bischof, 1995) and bioelectromagnetism (Adey, 1981; Becker, Selden, 1985; Oldfield, Coghill, 1988; Popp et al., 1989; Smith and Best, 1989, Smith, 1995).

David Bohm expressed a view that in human consciousness, what actually happens in its ground level - beyond neural states representing results of only activity related to aware consciousness- may be very fast and related to prespace, the implicate order behind space-time, to a creative factor, from which the whole phenomena and the space-time structure enfolds. These fast mental 
processes have characteristics common to microphysical processes (Bohm, 1986). Ultimately, thinking is related to the unconscious until its deepest ranges.

The problem of creativity is present in every field of science (Laszlo, 1995). He suggested that quantum-vacuum interactions play a significant role in the fields of cosmology, physics, biology and consciousness.

There are thoughts, which are related to the execution of some functions of the organism (Libet's experiments). These are related to some kind of action potentials above a certain specific threshold or amplitude. Non-executive thoughts, which do not trigger bodily changes, do not necessarily develop well defined action potentials. I have developed the idea that the conscious mind works with information processed by deeper mind levels, which are not embodied in activation potentials, but by more subtle changes in the brain. It is well known that the speed of information processing of the conscious mind in average conditions is estimated to be around $\mathrm{C} 1=100 \mathrm{bit} / \mathrm{s}$, while the information processed by deep mind may be estimated to be larger than the information reaching the organism from the external world through the outer senses, which is around $\mathrm{C} 2=10^{9}$ bit/s (see e. g. Elsasser, 1958, Griffith, 1970, Drischel, 1972, Woody, 1982, Silbernagl, Despopoulos, 1991, Scheffer, 1994). To have a feeling of these numbers, the often cited examples are the reading speed, estimated to be $50 \mathrm{bit} / \mathrm{s}$ if one needs 20 seconds to read a page of 1000 bits (one letter is around 4.5 bit, but there is a considerable redundancy in a page). One may assume that speed reading is an attempt to use the eye and conscious mind at full speed. An extreme speed reading champion reads less than 100 words per second, i.e. approximately $500 \mathrm{bit} / \mathrm{s}$, because in an ordinary text you have less than 5 bits per word (Shannon, 1951). On the other hand, a TV screen mediates $10^{6-7} \mathrm{bit} / \mathrm{s}$, estimated by the number of pixels and their information content (Scheffer, 1994). The deep mind processes information from the outside world coming into the organism through external senses, and, parallel with it, the input data coming from the deeper mind levels. Our behaviour expresses around $10^{7} \mathrm{bit} / \mathrm{s}$ through speaking, mimics and bodily movements. The ability to express information through speaking, being definitively slower than reading, is estimated to be around only $10 \mathrm{bit} / \mathrm{s}$, if we take a time of $100 \mathrm{sec}$ to read a page. The all-ornothing picture of the neurones representing 1 bit information expressed by their ability for activation (firing) or inhibition cannot store and process such a gigantic flow of information.

\section{Quantum-Vacuum Interactions in the Brain}

Eccles $(1986,1994)$ built up his model of thought-process based on the probabilistic change of the quantum mechanical wave function, assumed to occur without energy supply. Actually, the reduction of the quantum wave function 
needs energy, as it is pointed out by Károlyházi (1966), recently by Albert and Vaidman (1989) and Pearle and Squires (1994). I assume that the energy is taken from the zero-point-fluctuation of the vacuum field, as described by quantum electrodynamics (QED) or stochastic electrodynamics (SED; Boyer, 1975). This assumption is inspired and substantiated by the quantum-vacuum interaction (QVI) theory of Ervin Laszlo (1995). I assume that the collapses are associated with the sizes of the relevant thinking units ('brains'). This assumption seems to be plausible if we regard the experimental results of synchronisation processes of neurones in diverse part of brains (Crick, 1994). These assumptions, if they turn to be correct later on, give the strength of the main arguments below.

Here we first calculate the size of a brain working with a kind of material carrier. The Heisenberg uncertainty principle tells us that quantum measurements cannot be arbitrarily precise regarding both energy and time:

$\Delta \mathrm{E} * \Delta \mathrm{t} \geq \mathrm{h} / 4 \pi$

The above law limits the time-span of the total energy $E$ of virtual particles to $\Delta t$. Virtual particles are created and annihilated with energy $E$ for time $\Delta t$ in accordance with

$\mathrm{E} * \Delta \mathrm{t} \sim \mathrm{h} / 4 \pi$

Gu and Rauch (1994) noted that the coherency threshold (2) is the one at which the rate of uncertainty for the real particles is minimal and so is the critical value when the signal-to-noise ratio is at a maximum. Similarly, the relationship between the position and momentum of virtual particles in the quantum vacuum is $\Delta \mathrm{p} * \Delta \mathrm{x} \sim \mathrm{h} / 4 \pi$

Equations (7) and (8) describe constraints on the physical properties of virtual particles.

I assume that the quantum wave function of a real particle collapses as it interacts with the energy carried by a vacuum wave:

$\mathrm{E}$ (vacuum wave) $\sim \Delta \mathrm{E}$ (quanta)

Here for a real particle we note $p=m v$ and $E=p^{2} / 2 m$. For simplicity we adopt a co-ordinate system in which $p_{O}=0, E_{O}=0$. Then we can express position and energy together with momentum. Using $m$, a quantal carrier of mass as the basis of information, we obtain the following relationship between the overall size of a natural 'brain' and the time-scale of the information processing within it, using (9), (8) and (7):

$$
\Delta \mathrm{x} \sim(\mathrm{h} \Delta \mathrm{t} / 8 \pi \mathrm{m})^{1 / 2}
$$

Here $\Delta \mathrm{x}$ stands for the width of the quantum wave function of the real particle which carries the thought process in the actual brain. A collapsed wave function, a particle is in a quantum state which is best approximated by a wave packet. The spread in momentum (i. e. in the velocity) values implies that the wave packet will spread in time. The more localised a particle is, the more quickly it spreads. The same formula (10) is derived by Károlyházi (1974, formula 4. 1. 1), without applications in biology. Therefore, $\Delta \mathrm{t}$ has a meaning of a 
coherency length, $\tau$, the time of the spread for doubling the width of the wave function.

\section{Applications to Human and Cellular Brains}

First of all, it is interesting to calculate the material carrier of global human brain. It is possible to calculate the mass of this carrier with formula (10) if we use values of the parameters characteristic to the human brain. Using for $\Delta x=10$ $\mathrm{cm}$ and for $\Delta \mathrm{t}$ the time necessary for the development of an activation potential in a neurone is $\tau=10^{-3} \mathrm{~s}$ (S. Rose, 1973). Formula (10) then gives an exciting result of $\mathrm{m} \simeq 10^{-33} \mathrm{~g}$. This result suggests that the human brain interacts with the vacuum waves through the electromagnetic field quanta.

Now let us use formula (10) the other way round, looking for brains with electrons as material carriers of thought, with mass $m_{e} \cong 9 * 10^{-28}$ g. With the help of these given values, we can estimate the size of the macroscopic brain thinking with electrons:

$$
\left.L \text { (natural electronic brain, } \tau=10^{-3} \mathrm{~s}\right) \cong 10^{-2} \mathrm{~cm} \quad \ldots . .(11)
$$

This limit is close to the size of cells, namely $10^{-3} \mathrm{~cm}-10^{-2} \mathrm{~cm}$. This result means that if we want to construct a brain processing information through interaction of its electrons with vacuum waves, the brain has to have a size characteristic of the cells, if its biological characteristic time scale is $\tau=10^{-3} \mathrm{~s}$. The consistency of this result may indicate that cells process information through electron-vacuum wave interactions. Nevertheless, if cells absorb energy from the vacuum, it should be possible that they give back this amount of energy to the vacuum, otherwise the interaction may decelerate quickly. We know that cells are able to give back the energy from their free energy reservoir, a general characteristics of all living system (Bauer, 1920).

At the same time, the cells may simultaneously use a faster, lighter material carrier of information processing, because their environment is much smaller and therefore changes much more quickly. In the estimation of this time scale one can use the fact that the human organism processes $10^{9}-10^{10} \mathrm{bit} / \mathrm{s}$ information unconsciously, while at the same time the conscious mind is only able to cope with $10^{2} \mathrm{bit} / \mathrm{s}$ ( refs. cited above). If the time scale of the cells' information processing is proportional to the rate of the conscious information processing and that of the deep mind, which seems to be a reasonable assumption, then the timescale of this more subtle cellular information processing is $\tau=10^{-9} \mathrm{~s}$. This value is substantiated by the reaction rates in the interior of cells, known to be around $10^{8}-10^{12} \mathrm{~s}^{-1}$ (Ruth, 1989). Moreover, the lifetime of a hydrogen bound within a 
living cell is again $6 * 10^{-9} \mathrm{~s}$. A typical lifetime of the electronic excitations in normal metabolism is $10^{-8} \mathrm{~s}$ (Bauer, Borsdyko, 1936). Formula (10) with $\Delta \mathrm{x} \cong$ $10^{-2} \mathrm{~cm}$ with $\tau \cong 10^{-9} \mathrm{~s}$ then gives a value of $10^{-32} \mathrm{~g}$ for the mass of this material carrier, which can be appropriate for the mass-energy of a photon $(\mathrm{E} \cong 10 \mathrm{eV})$. This result points, interestingly enough, to the presence of electromagnetic waves in the cell regulation. Independently from the ambiguity of the time scales accepted here, if the trend of acceleration of thought processes towards deeper mental levels is real, than we are supplied with an insight by formula (10) that electromagnetic processes dominate in a certain mental depth. I have to point out, that bioelectromagnetism is based on the fact that cells are regulated by electromagnetic processes.

Now let us look for the time scale of the human brain, in connection with the electron-vacuum quantal interaction! We use $\mathrm{m} \simeq 10^{-27} \mathrm{~g}$ for the electron mass, and $\Delta \mathrm{x} \cong 10 \mathrm{~cm}$, the time scale $\Delta \mathrm{t} \cong 400 \mathrm{~s}$. A longer time is needed for the brain to extract information and energy from the vacuum field through electrons than through photons. Regarding the fact that the large molecular tracks are built up by a long series of electronic events, we may get a physical picture of the time scale of long-term memory.

\section{Coupling Between Global and Local Brains}

Formula (10) suggests that the thinking process takes place in different time and space scales. Nevertheless, any organisation should act as an integrated unit, a system regulated globally, with all the necessary information gained. This fact points to a need to couple the different scale processes, transferring their information content to the level of decision making. We can study the nature of these couplings if we consider formula (10) from that point of view.

Let us assume, that the (necessary, but not sufficient) condition of any coupling between the different level (global or local) processes is the identical time scales, as any direct interaction may occur only between two simultaneous processes. Now we can start to look at what happens if the neural (local) and global brain phenomena are coupled. Using the neural time scale of $\tau=10^{-3} \mathrm{~s}$, with the electrons extended to the brain as a whole $(\Delta x=10 \mathrm{~cm}$ with formula (10)), a material carrier may contact in a neural time scale in a whole range of space localisation. As we take smaller scales, the mass of the carrier grows if we fix the time scale, in accordance with formula (10). At each selected size two masses should be followed: one that arise from (10), growing as $\Delta x$ decreases, and another which is actually present in the selected size of volume in the human brain, $\mathrm{m} \simeq \rho *(\Delta \mathrm{x})^{3}$, decreasing as $\Delta \mathrm{x}$ decreases. The two masses are equal when $\Delta \mathrm{x} \simeq 10^{-6} \mathrm{~cm}$. The corresponding mass is $10^{-13} \mathrm{~g}$, a value just at the upper limit of the quantal range of the microscopic world as given by Károlyházi (1966). One 
can visualise the coupling now as the electron, subtracting information from the vacuum, present in a free state, interacts with a part of a neurone. The size and mass of that part of the neurone, which may be coupled to the global brain on the neural time scale, is close to the microtubules. It is interesting to note here that recent measurements of electromagnetic emission from living matter at CERN show that the time-dependent pattern of the emitted biophoton radiation shows a self-similar structure through ten orders of magnitude (Popp, 1994). This fractal structure of the emitted radiation enhances the empirical basis of the global-local coupling.

\section{Frequencies of Interaction Between Different Brains}

Now we are ready to estimate the wavelength of the information-carrier substances. The energy of wave quanta is $E$ (wave) $=\mathrm{hf}$, where $\mathrm{f}$ is the frequency of the wave with a wavelength of $\lambda=v / f$. At first, we can work with a quanta of waves having a mass-energy $\mathrm{m}=\mathrm{E} / \mathrm{c}^{2}$ in (10). In this way we can obtain the result by the following formulas:

$$
m=(h \tau) /\left(\pi \lambda^{2}\right)
$$

The relation between the wavelength of the informative wave and the brain's space-time dimensions is

$$
\lambda \cong 8 \pi(\Delta x)^{2} /(c \tau) *(v / c) \cong 2 h /(m c) *(v / c)
$$

For the human brain we take $\Delta x=10 \mathrm{~cm}, \tau=10^{-3} \mathrm{~s}$, and $v \cong c$. This results in $\lambda$ $\cong 8 * 10^{-5} \mathrm{~cm}=800 \mathrm{~nm}$, or $f \cong 3 * 10^{14} \mathrm{~Hz}$ which is at the blue edge of the visible spectral range. For cellular information processing $\Delta x=10^{-2-3} \mathrm{~cm}, \tau=10^{-10} \mathrm{~s}$, and the wavelength $\lambda \cong 3 * 10^{-6} \mathrm{~cm}=300 \mathrm{~nm}$, $f \cong 10^{15} \mathrm{~Hz}$, which is within the ultraviolet spectral range. Remarkably, these two wavelengths are close to the value of $l_{\text {crit }}$. The frequency is $10^{15} \mathrm{~Hz}$ which is just the value belonging to the activation energy of the cells' enzymatic reactions. What is more, the spectral range belonging to the mitogenetic radiation is just in the same one. The mitogenetic radiation is observed to be emitted by dividing cells at and shortly before cell division. The history and the present state of the experimental investigations on ultraweak photon emission/mitogenetic radiation is presented by Ruth (1989, and F. A. Popp, K. H. Li. And Q. Gu, 1992). Notably, the above calculated wavelength is the same one at which the energy surplus of living protein is radiated away in the process of dying (Bauer, 1935, this phenomenon is known as the "degradation radiation", see also Ruth, 1989). Ervin Bauer, the greatest forgotten biologist of the century, developed a quantitative mathematical description of the most basic biological processes: growing, metabolism, dying, replication and sensitivity. He showed that in a living organism the molecules are in a deformed, elongated and electrically polarised state containing surplus, free energy, i.e. the free energy is EM energy. 


\section{Quantum Energy Transfer Between the Brain and the Material Carriers of Thought}

Let us estimate now the amount of energy transfer between vacuum and quanta. The uncertainty principle (7) gives us a tool to estimate the energies relevant to the individual time scales. When using $\tau \cong 10^{-3} \mathrm{~s}$, we have for $\mathrm{E} \cong$ $5 * 10^{-25} \mathrm{ergs}$, while for $\tau \cong 10^{-9} \mathrm{~s}, \mathrm{E} \cong 5 * 10^{-19} \mathrm{ergs}$. The energy change of the electron localised to a human brain is estimated to be

$$
E=p^{2} / 2 m \cong h^{2} /\left(32 \pi^{2}(\Delta x)^{2} m\right)
$$

i. e. $10^{-30}$ ergs with $\Delta \mathrm{x}=10 \mathrm{~cm}$ for electrons.

On the physical basis presented here one can construct the following chain of events for an interaction between the mind and the brain.

In the first step the information is contained and mediated by the vacuum field. These vacuum waves may interact with electromagnetic waves in giving them their information in the second step. The electromagnetic waves then may interact with the biomolecules of the brain, like sunshine interacts with chlorophyll molecules transferring the energy of the sunlight into chemical free energy. From this available chemical energy the activation potentials of the neural networks are built up. Nevertheless, all four steps could be simultaneously influenced by the vacuum waves.

The frequencies of the vacuum waves obtained here are remarkably close to the observed frequencies at cell divisions. This circumstance suggests that the way vacuum waves interact with material waves can be a resonant phenomenon. The vacuum waves may transfer their energies and information content to material waves at the same frequencies. The real energy transfer could be necessary only at the onset of some material processes in an upper level of the mind. Here, I suggest a picture in which the different levels of our minds may work with progressively more subtle material carriers, while the deepest one works with vacuum waves without any net energy transfer taking place in the end, because the energy taken out from the vacuum may be put back by the brain itself when reading important information from the psi-field. It could be the reason why only living organisms with a significant free energy content are able to react on the basis of the information read out.

\section{Quantum-Vacuum Interaction in the Universe}

The sizes of a brain thinking with electromagnetic waves are within the range of

$$
\mathrm{L}(\mathrm{EM} \text { brain }) \cong 10^{-8} \mathrm{~cm}-1.6 * 10^{9} \mathrm{~cm} \cong \mathrm{R}(\text { atom })-\mathrm{R}(\text { Earth })
$$

being the limiting values. The atomic size arises from formula (10) working with $\tau=10^{-14} \mathrm{~s}$ as the lifetime of the van der Waals bonds choosing for " $\mathrm{m}$ " the mass 
of the most energetic electromagnetic waves $\mathrm{m}$ (gamma rays $) \cong 10^{-27} \mathrm{~g}$. The upper limit arises from the time-scale of the global brain, $\tau \cong 10^{3} \mathrm{sec}$ and the lower limit from the mass-energy of the least energetic electromagnetic waves $\mathrm{m}$ (radio waves) $\cong 10^{-43} \mathrm{~g}$. It is interesting to note here, that the frequency belonging to the largest electromagnetic brain is around $1-100 \mathrm{~Hz}$, in the range of the brain and Schumann terrestrial EM waves.

One can calculate the wavelength belonging to a thought process occurring in a cosmic dimension with the size of the Universe. Using for $\Delta \mathrm{x} \cong \mathrm{R}$ (Universe) in (10) we get for $\lambda$ (Universe)

$$
\lambda \text { (Universe) } \cong 2 \pi(c \tau)(v / c)
$$

Taking for $\tau \cong$ the age of the Universe, $\mathrm{c} \tau \cong \mathrm{R}$ (Universe) because the Universe is expanding with a velocity close to the speed of light. It means that the size belonging to a thought process occurring in a duration with the age of the Universe has just the same order of magnitude as the size of the Universe.

Using different values for t belonging to a certain system in (16) we get different values for $\lambda$ which belongs to a vacuum wave of different wavelength. Equation (16) offers the description of the coupling between the thought processes of the Universe and its organic elements, another global-local coupling. Namely, using the time-scale of the human consciousness, $\tau \cong 10^{-3} \mathrm{~s}$, we get the resonant wavelength of the Universe to Man as $\lambda \cong 2 * 10^{8} \mathrm{~cm}$ when using a value of $v \cong c$. This magnitude is again close to the size of the Earth, and with $v \geq c$ it is possible to get even larger sizes. The size of a brain thinking with vacuum waves can be

$\mathrm{L}$ (vacuum waves) $\cong \mathrm{L}$ (human brain), $\mathrm{R}$ (Earth), $\mathrm{R}$ (Sun), $\mathrm{R}$ (Universe).

The different vacuum waves couple us in a different scale to the cosmos and to our bodies and brains, while the electromagnetic and electron waves present couplings between our environment, our brains and local neural processes. These couplings to the different scales of the outer world represent couplings between our different mind levels, simultaneously. In this context it is important to note, that these outer sources of informations - the Earth, the Sun, the stars, and the Universe as a whole - do show a whole range of generalised organic processes (Grandpierre, A., 1995a, 1996a,b,c,d).

In my essay (Grandpierre, A., 1995a) I argued that every element of the Universe is a kind of a double-pyramid consisting of hierarchical levels i.e. conscious mind, deep-mind, genetic-mind, cosmic mind (inner world pyramid of a human being), Earth, Solar System, Galaxy, Universe (outer world-pyramid of a human being). The difference between the organisms of the Universe is only what is outer and what is inner for them, but the levels in their pyramids are similar, consisting of the same constituents. In this context it is interesting to note, that our calculations show that the different organisms interact with the same range of universal fields, but their sizes determine, what is 'outer' and what is 'inner' for them, and which are the long and short wavelengths compared to their physical sizes. 


\section{Spontaneous Targeting}

The fundamental difference between the inanimate, inorganic systems and organic, self-organising systems is the appearance of such life phenomena within the latter ones as metabolism, sensitivity, growth, multiplication and homeostasis. It is clear that an inorganic 'object' is one which lacks free energy and mobile 'tentacles', mobile external sensors and executive instruments. We observe in nature that all 'objects' with free energy and movable surfaces spontaneously organise themselves into 'systems', e.g. atoms, molecules and crystals. 'Systems' are objects which are mobile enough to organise themselves into a hierarchical order, generating a level where they can act freely and so can organise their activity in their environment. This spontaneous organisation is 'automatic', it is a universal characteristics of material 'objects', therefore we usually ignore it. Nevertheless, spontaneity is a remarkable property of the system formation from its elements. The formula $\mathrm{H}_{2}+\mathrm{O} \Rightarrow \mathrm{H}_{2} \mathrm{O}$ expresses, that by mixing the components water molecules form automatically, spontaneously if the mix is supplied with the necessary amount of energy to trigger the process. But the question arises: how do the molecules of hydrogen and oxygen find each other? If they follow a heat motion, a brownian random motion, only a minute part of the molecules with proper impact factors (distance and velocity) could collide in the manner necessary to form the compound molecules during the short time interval given by the trigger heat and the explosion. This observation makes it clear that a yet unnoticed 'spontaneity' acts as an organising factor even in the sphere of inanimate systems. A new and independent evidence appeared and this underlies the above argument. A recent result substantiates the spontaneous targeting phenomenon in $\mathrm{H}_{2}+\mathrm{O} \Rightarrow \mathrm{H}_{2} \mathrm{O}$ ( Hemley, 1995 ). This reaction between hydrogen and oxygen is surely one of the best studied chemical reactions, but details of the reaction kinetics have always been enigmatic. Loubeyre and LeToullec (1995) found that the normally explosive reaction is shut down by pressure and a new compound is formed. It means that the factors organising the reactions are sensitive to pressure and temperature.

The organisation of the biologically active configurations of proteins from an unfolded polypeptide chain presents another enigma known as the Levinthalparadox. C. Anfinsen showed in the early 1970s that a protein having been unfolded by chemical denaturants could refold spontaneously when the denaturing conditions were reversed. Levinthal pointed out in the late 1960s that the number of possible states of an unfolded protein is larger than $10^{60}$. Assuming 
that the protein "hunts" for the biologically active configuration in a random process at a rate set by vibration frequencies (about $10^{13}$ searches per second), for a single protein molecule to arrive at the folded state would take longer $\left(10^{30}\right.$ times) than the age of the Universe. But proteins can fold completely within hours - sometimes within milliseconds - and early steps occur on time-scales far shorter than milliseconds. It is shown, that interactions between secondary structures i.e. long-range intramolecular interactions between $\alpha$-helices and $\beta$-sheets - are important in the folding process, which is sensitive to temperature and electromagnetic fields (Callender et al., 1994). Remarkably, new and independent results substantiate our arguments on the phenomena of spontaneous organisation. Hess and Mikhailov (1995) pointed out, that in living cells the enzymatic subsystem within normal conditions represents a coherent molecular network, the entire population of the network is in continuous communication and undergoes collective evolution. These molecular networks are in close analogy to neural networks and insect societies. Mikhailov and Ness (1995) showed that when a new protein molecule is produced at a membrane, it is loaded into a budding vesicle which then moves through the cell until it reaches its target at another membrane location. They presented evidences for their assumption that vesicles detect the direction leading to their targets and can actively move towards them. Thus, the behaviour of vesicles resembles that of entire cells in chemotaxis and in the phenomenon of cell-to-cell communication. The intrinsic reference frame needed for detection of the motion direction by vesicles could be provided by the intracellular chemical gradients and/or by the electrical fields present inside a living cell.

The same problem of the existence of a targeting mechanism seems to work in the olfactory field, as well. How could the odorant molecules find automatically their receptors? Lewis Thomas (1974) noted that eels have been taught to smell two or three molecules of phenylethyl alcohol. An average man can detect just a few molecules of butyl mercaptan. How the olfactory cells are fired by an odorant is not known. The substance may become bound to the cells possessing specific receptors for it and then may just sit there, somehow displaying its signal from a distance.

I suggest the term "spontaneous targeting" for this general phenomenon present in the inanimate and animate worlds as well. Spontaneous targeting is just a sub-phenomenon of the more general spontaneous organisation pervading the whole Cosmos (Endre K. Grandpierre, 1996a, and also in this volume). This spontaneous organisation factor is the one which organises any system with the proper conditions (free energy, movable perceiving surfaces, etc.) into biological organisms. Of course, a totally inanimate object will never 'resurrect' to an organised system, therefore the mere presence of life anywhere in the Universe indicates the universal presence of an organising factor. 


\section{Global Organisation and Action-in-Distance}

If a system is able to develop a level of phenomenon which is independent from mere physical and environmental determinations, it develops its own laws on this level. In order to be able to follow these laws, it has to find a way to handle the energy and information which reached the system from a global perspective, transporting the energy and information easily to the place where they serve the global project. This 'global organisation' assumes the existence of an 'action-in-distance', first of all, because the global organising centre has to contact - within the shortest time of the reaction time scales - not only the state of affairs in the whole system, but also it has to process the information and reach the proper decision. The system has to be 'transparent' for the information needed. On the other hand, the system also has to be filled with free energy stores in order to make the energy easily available when the decisions reach local parts of the system. This informational transparency requires an informational actionin-distance. If there an informational transparency exists within the system, it may also be used to gain access to interact with other systems in the informational level. This intersubjective informational transparency is the first form of perception that nature applied, in generating always the global system first and the subsystems subsequently, e.g. the Metagalaxy first and the Galaxy afterwards, the species first, the individual later. Therefore, informational transparency is as basic for the individuals of a species as for the cells within the body of the organism. Actually, this informational 'action in distance' is based on a cooperation of similarly tuned units of organisation, at cells, organisms, groups, in and between different species, until the biosphere as a whole and the Universe as a whole. This primal perception is the way how cosmic tuning (Grandpierre, A., 1992), and an anthropic, life-containing Universe (Barrow, Tipler, 1986) are produced. The transparent exchange of information is a kind of perception which was necessarily developed upon the origin of Metagalaxy, and divided afterwards into its subsystems, all of which kept some primal patterns of its antedescent organism in order to be able to organise itself as a whole. This informational perception turns out to be a primal, cosmic perception which developed before the origin of external senses. The primal perception is a direct unfolding and exchange of all basic information present in the Cosmos. This primal perception is the first - still unnoticed- life phenomenon developed in the Universe. The primal perception still preserved some of its characteristics in the phenomena of group effect.

\section{The Fundamental Problem of Electromagnetism and Quantum Physics}


Electromagnetic fields are known to mediate information extremely effectively through e.g. light waves. The wave-particle duality has been known since the two-slit experiment of Young in 1801. This duality describes a spherical spread and a parallel guidance, as expressed in a local sudden collapse into a 'particle', photon at the site of interaction. The nature of this duality is still not well understood (Newton, Wigner, 1949). I suggest that the solution of this fundamental problem of the field theories of physics, in electromagnetism as well as in quantum field theories, lies in the fact that an immediate mediator field exists which mediates information or structural patterns from the wavefronts immediately into the place of interaction, e.g. the site of observation. In my interpretation besides the wavefronts of the electromagnetic waves an ultrafast or immediate 'mediator' field exists which is able to transform the wavefront in a glance into a photon particle. This mediator field acts faster than the speed of light, immediately, and gives a clear picture on the nature of electromagnetic wave propagation. This ultrafast mediator field is able to interpret the fundamental variational principles of physics. This EM mediator field exchanges energy and information between the extended magnetic field of the current and the circuit itself. The existence of this fundamental field is the only solution to the still unrecognised fundamental problem of electromagnetism i.e. the energy of the EM field seems to be present in its whole amount in the circuit and, at the same time, in the EM field. If it means an actual simultaneity, it would lead to a doubling of the energy, which is absurd. Therefore the only solution is the one I suggest here, and that is an EM field which is able to 'act in distance'.

As early as 1892 Maxwell recognised that the EM energy is present in the circuit and the EM field simultaneously. He understood that the current is able to perform electrolysis locally, to develop Joule-heat locally, and the ability to do work locally involves local energy. At the same time, the energy is also present in the form of field energy. Maxwell suggested that a part of the EM energy is present locally and the remaining part is present globally (1892, Vol. II, p. 212). Nevertheless, the calculations lead to equal amounts of energy, and when one form of EM energy changes, the other form changes simultaneously. Feynman, the founder of quantum electrodynamics, expressed a view that the energy is present in the field globally- but he is silent about the local EM energy (Feynman et al., 1963). The presence of this primary EM field offers for the first time the actual, immediate 'action in distance', which has a significance of overall importance, in the understanding the nature of the field of consciousness, as well. It is interesting, that Maxwell himself, in the last chapter "Theories of action at a distance" of his book recognized the instantaneous character of some EM effects: "An electric particle sends forth a potential, the value of which ee' $/ r$, depends not only on $e$, the emitting particle, but on $e$ ', the receiving particle, and on distance $r$ between the particles at the instant of emission" (Maxwell, 1892). This primary EM field may serve as a physical basis for the 'spontaneous targeting' introduced above, the 'spontaneous collapse' of the waves to the site of interaction or observation, thus solving the central measurement problem of the present day 
quantum theory, and the 'primary perception', which is a yet unnoticed effect, but discovered independently and simultaneously by the present author and Endre K. Grandpierre (this volume). This primary EM field may help in maintaining the 'global organization' and 'informational transparency' described above.

\section{The Source of the EM Field}

The presence of the immediate mediator EM field is clear from the followings, as well. Let us imagine the sudden appearance of an electric charge at a certain point. We know that the law of conservation is valid for the electric charges but the thought experiment also works with a sudden separation of a new-born electron-positron pair. Regarding the fact that the EM waves spread with the speed of light, and thinking that they start from the appearance of the charge - or the separation of the dipole -, we have to think that the electromagnetic field of the charge propagates with the speed of light. If the energy of the charge is in the field then with the spreading of the EM wavefront the energy in the field grows. But the electric charge conserves, therefore its energy and charge do not change. Following this line of thought we can think that the conservation law of energy is violated. Thinking the same thought experiment with a suddenly separated dipole, the sudden appearance of the dipole leads again to a continuous propagation of the EM field, even if we stop the separation at a certain moment. This means that the field is able to rearrange itself from one form into another form, and the expanding EM field is able to draw energy from its previous, latent form. The three forms of EM fields- wavefront, photon, and coupling mediator field, are able to exchange energy and information within each other immediately, as if they were one unique existent, or living in a complete symbioses. They may be regarded as being in a resonant coupling. I suggest, that the collective consciousness field extends this symbiosis to the overlapping particle mediated fields, like the acoustic or the olfactory field, as well as to other forms of vacuum fields besides the EM forms, the quantum-vacuum holographic fields (Laszlo, 1993, 1995). Their symbiosis, the inclusion of all of them into resonant coupling, is the key generative factor of the flexible, ultrasensitive organisation phenomena observed in the Universe, biosphere and societies. I suggest that the spell of the music may be understood by the coupling of the acoustic field of the body to EM vibration fields.

\section{Collective EM field of the Biosphere}

The EM field, as a part of the consciousness field, is shown to be able to directly trigger electric activity in the neuronal cells. On the other hand, the EM field emitted by the brain's activity is a measurable field. This result makes 
available a physical means for measuring consciousness field from point-to-point, for measuring the guidance of the consciousness field (or psi-field) between two people. Human brain works with a power of 20 Watts. We know that large amount of this power becomes waste heat and cools the brain. Nevertheless, all the energy produced by the organism in the course of metabolism goes through a significant step, the free energy, which is in direct relevance to EM energy. Since all the energy of metabolism goes through the EM phase, all the energy has to be present simultaneously in the EM field energy, a significant part of which leaves the body. We may think that if later on this EM energy is transformed into other forms of energy by mechanical work or heat, this is irrelevant in our estimation of the environmental EM field of the organism. Nevertheless, this view is not correct, if, as we have shown, all the EM energy of the organism is simultaneously present in the environment.

Mankind's brain activity involves a work of $10^{11}$ Watts, comparable to the electromagnetic power entering the earthly magnetosphere from the solar wind. The biomass of the Earth is a substantial factor of the source of the EM fields at the surface of the Earth. Scott (1962) measured the electric field of a bean root in the surrounding solution of the root. The measured total power dissipated electrically to the environment by the root is $10^{-9} \mathrm{~W}$. Remarkably, the electric field shows a spontaneous and truly endogenous rhythm with a 5-minute period which coincides with the periods of the acoustic modes of the Sun. It is interesting to note here the remark of Cox and Giuli (1968) on the close value of the specific energy production rate of the solar core and of the specific energy liberation rate of the human metabolism, both of which are around $100 \mathrm{ergs} / \mathrm{g} / \mathrm{s}$. The so-called dry-matter content of the biomass is $846 \mathrm{~g} / \mathrm{m}^{2}$, i.e. $4.310^{17} \mathrm{~g}$, which, taking a factor of ten for the water content, would give a value of $10^{14} \mathrm{~W}$ (as we know that $80 \%$ of the mass of the living matter is water). The plants of the biosphere transform half of the energy of the incoming solar radiation to its plant matter, i.e. $1.7210^{17} \mathrm{~W}$. One percent of this energy is transformed to energy contained in form of food. The original living form of solar energy as it was firstly bound in plants when reaching the food-eater predators, suffers a tenthousandfold loss, to $10^{13} \mathrm{~W}$ (after Odum, 1971). The produced biological free energy, as calculated from the dry-matter content, is $20810 \mathrm{Kcal} / \mathrm{m}^{2} /$ year of the plants, $3368 \mathrm{Kcal} / \mathrm{m}^{2} /$ year of the herbivorous animals, and $21 \mathrm{Kcal} / \mathrm{m}^{2} /$ year of the large predators (Fábián et al., 1975). These numbers give a biological energy of the plants around $1.4310^{15} \mathrm{~W}$. If only ten-thousand part of this biological free energy was expressively radiated out to the environment, this value still would be significant enough to be comparable to the geophysical factors. We have to realise, that plants, and EM fields of animal and human origin may be a substantial part of our EM environment. The EM field of human origin is of a smaller amplitude, but this relative difference may be balanced by the relative ease with which we can tune to human frequencies. If we are able to tune ourselves to the plants' field, we can feel their overwhelming, galvanising EM fields. 


\section{Collective EM field of Human Subjects}

Burr (1935) formulated a concept that EM fields organise the living processes. "The pattern of organization of any biological system is established by a complex electrodynamic field which is, in part, determined by its atomic physiochemical components and which, in part, determines the behavior and orientation of those components. More than establishing pattern, it must maintain pattern in the midst of a physiochemical flux. Therefore, it must regulate and control living things, it must be the mechanism, the outcome of whose activity is 'wholeness', organization, and continuity."

Burr (1956) measured the relatively steady-state standing potential of a tree for more than a decade. The potential shows diurnal, monthly, and seasonal variations of considerable interest and, over the years, and suggested a correlation with sunspot activity. It has been adequately demonstrated that a living organism, a tree, is an electric system, exhibiting all the properties of an electric field. It is remarkable that in its most fundamental electromagnetic regulation the cosmic effects appeared so pronouncedly.

Ravitz (1962) was able to show, by working out 50000 field determination on some 500 human subjects at Yale, Duke, and University of Pennsylvania Schools of Medicine, that "the variations of the EM fields of the human subjects provide an objective profile of similar variations in the feeling and behaviour states, and open the door to both long- and short-range predictions in time. Electrocyclic phenomena seem to be governed both by exogenous and endogenous factors. Primacy of the exogenous component is suggested, however, not only by plotting similar field excursions on diverse representatives of the plant and animal kingdoms within the same intervals, but also by demonstrating parallelisms between simultaneously recorded atmospheric, earth, and tree potential differences."

Biological organisms show extreme sensitivity for external EM signs, as the new branch of science, bioelectromagnetism has discovered (see the references above, Sect. V.). Recently, Kuznetsov (1982) reviewed the results of laboratory experiments with synchronous yeast cells Candida Utilis. "The presence of external rhythms' influence on the yeast cells growth in a batch cultivation system was established. The results of statistical processing of the experimental data showed the statistically significant presence of $160.009 \pm 0.006$ minute oscillations in the variability of the specific growth rate of the yeast population. The fact testifies in favour of the 160.01-minute global solar oscillations influence on the Candida Utilis growth rate." These oscillations were 
independently discovered in 1976 by two solar research groups in Crimea and Birmingham. Their results pointed out that the solar surface shows oscillations with a 160-minute period. Arguments proving the existence of this period in solar oscillations are given by Kotov (1995). The amplitude of this oscillation is low, only $1 \mathrm{~m} / \mathrm{s}$, changing permanently. The origin of this oscillation, contrary to the 5minute oscillations, is not known, and inexplicable by the standard solar model (Kotov, 1985).

It is well known, that the ionosphere and the surface of the Earth form a cavity for the electromagnetic waves, therefore every electromagnetic disturbance in its attenuation may be transformed into a standing wave determined by the size of cavity (Schumann and König, 1954). The standing terrestrial electromagnetic waves, termed as Schumann waves, have a characteristic frequency of $7.5 \mathrm{~Hz}$, coinciding with the range of the most creative brain EEG frequencies, $\alpha$-waves, which are produced also in the REM phase of sleep. Moreover, the time characteristics of Schumann oscillations and the EEG $\alpha$-rhythm, as well as stormrelated fluctuations of electric field and the EEG $\delta$-rhythm show a noticeable similarity in their temporal variations (König, 1989). These circumstances may substantiate a hypothesis that human brains/minds are able to interact with the information field of the terrestrial organic self-maintaining system.

Human consciousness fields primarily interact at the $\alpha$-level in frequencies around $7.5 \mathrm{~Hz}$, therefore the creative state of mind is the same one as the most influential source of the collective consciousness field. Moreover, the human $\alpha$ field interacts with the earthly $\alpha$-field, with the Schumann waves. The $\beta$-field, the field of awake consciousness, in the present societies seems to be largely inactivated and, in contrary to the alpha-field, does not form an effective collective consciousness field. The reason for this anomaly is that the awake state is not in a continuous resonance with the $\alpha$-field, as a result of the schism of breaking our mind into two antagonistic parts (see Grandpierre, E. K., this volume). This psychic anomaly is the factor behind the sporadic and low-level ESP abilities of the Homo sapiens sapiens. Inactivated information fields can only be actualised if consciousness turns against its deeper generating levels. The $\beta$ field of individuals is generally in an extraordinarily low-intensity state because most part of its energy is consumed in the repression of the deep-mind. Nevertheless, the way in which we can reach healthier consciousness fields is the development of the high-intensity $\beta$-field, which is filled with the powers of the deeper mind levels in a natural resonance. The $\delta$-and $\vartheta$-fields are related to cosmic electromagnetic wave fields (Grandpierre, A., 1996d). The natural sources of collective consciousness fields are the plants, animals, (nonmanipulated) humans, the Earth, and, through the cosmic interface of the Earth, the magnetosphere, the Moon and the Sun, and, through the heliosphere, the whole Galaxy and Universe. Exploring and understanding the working of consciousness may help in tuning to its natural, more powerful sources, regaining 
a harmony between its main constituents, and opening a perspective to the experimental exploration of collective consciousness fields.

\section{The Physics of the Evolution of Consciousness}

The evolution of consciousness - as the evolution of the Universe shows us - actually is in contrast to the presently accepted evolutionary theories, which want to build up the whole from the parts. In reality, evolution started from the whole and progressively differentiated into parts, from the timeless-spaceless form (e.g. the 'implicit order', or 'pre-space' of D. Bohm and J. A. Wheeler), through galaxies, through the development of the Solar System and the Earth, the appearance of the biosphere and mankind, until the development of smaller and smaller subsystems of consciousness, until the human individual. 'Cosmologies of wholeness' are emerging (see Laszlo, E., 1993; Harris, 1988). All of the cosmic evolution formed sub-systems within systems. Evolution begins with 'systems', 'elements' develop only later on. Every system originates as a subsystem of a larger, inclusive system. The organisation of the sub-system is made by the creator system, and the organisational factor acts from within, as well. This fact assumes that the creator system is in a certain way transformed into the to-becreated subsystem, the 'whole' is transformed to the 'part'. This global-local transformation is a necessary condition of the generation of the new system. Therefore the Universe acted continuously as an agent with organisation ability, and is progressively transformed from the largest of its subsystems into the smallest ones. The trend of evolution is simultaneously going towards a higher complexity and this way towards more and more complex subsystems, and in this way the real evolution is also accompanied by the state of becoming more and more complex and towards higher and higher forms of consciousness. Ervin Laszlo remarked: "Evolution acts on species and populations and not only - or even mainly - on individual reproducers. Individual variations do not contribute significantly to the emergence of new species." This trend, the primacy of 'global' over 'local' appears in the history of mankind (Grandpierre, E. K. this volume), starting with cosmic consciousness in the Golden Age of mankind. Later a break set up in the trend of human evolution, attempting to cut down the 'whole' from the 'part', the Cosmos from the living beings. The complex subsystem of human collectives preferred only one side of this cosmic trend, the more and more divided and separate complexity, the specification to individual human being, at the expense of general context and cosmic laws, drawing away and retiring from the growing collective order, loosing the connections to the larger, embracing levels of existence. As Andras Angyal expresses it the autonomous, self-maintaining tendency dominates over its dual brother, the 
homonymous, self-completing tendency (1941), the basic need for direct, sensual, artistic life-experiences. According to my research, the three inevitable motivating, life-long motivational instincts in our lives are the life-instinct, sustaining our individual life, the species-instinct, sustaining the life of our species, and the world-instinct, sustaining the life-functions of the Universe. The world-instinct is the basis of the other two, and it involves the imagination, intuition, curiosity, the desire for a meaningful life, to form healthy, alive communities, to correspond to larger units, to the Nature and the Universe (Grandpierre, A., 1991), therefore it is the world of the primary perception.

If we do not want to leave the road of cosmic evolution for ever, we may find again the path how to reveal our natural completion, the already hidden powers which the all-embracing cosmic evolution generated in our genes and basic constitution. Unfortunately, it has not been explored until now, how far we reached from our first-handed, natural drives, and what is the meaning that the Universe mediates to us. In order to form again a human, collective society, in which every individual sees the meaning of her/his activity and life, a meaning which is able to give an ultimate, lifelong satisfaction, we should recover the destination of mankind, and, besides it, the destination of the Universe. There is not any other task, which may be able to give a common perspective to all of us, than to explore and regain our destiny, to regain the harmony with the Nature and the Universe. Only this elevating and touching task may give back our harmony with ourselves. To do this, first we have to explore the nature of the Universe and understand the super-organism called biosphere - an organism with a collective consciousness.

\section{Origin of Consciousness and its Relation to Emotional States}

Psychological researches teach that consciousness is vital when it is filled with emotional drives. Positive emotions enhance the dominating role of the neocortex in the brain activity ( Völgyesi, 1962). Our research (see Endre K. Grandpierre, this and a later volume) shows, that the basic and first step of any conscious activity is an interaction. If consciousness works through EM fields, its activity in every step involves changes in its EM field and the interaction of its EM field with another EM field - outer or of an inner subsystem. It means that EM induction results, which generates naturally a higher level of electromagnetic activity besides the overlapping and superposition of the two interactive EM fields. Consequently, the interactive EM fields when they are active, generate a subsidiary EM field, a 'daughter' field. This induction effect is suggested to be the physical basis of the 'group effect', the enhancement of the basic activity level when entering into interaction with another human being, consciously or without being aware of it. Therefore, the consciousness can not be regarded developed and healthy, if its 'exploration drives' and 'general activity drives', 
emotional motivations and desires are passive, and are hindered by the aware consciousness. Consciousness develops through the phenomenon of 'emotional infection', widespread among children, and also present in rituals and when masses of people form a community. In new-born children, the movements originate from spontaneous emotional reactions, their sources are within the emotional system (Wallon, H., 1946). "At the origin of evolution, in contrast with the traditional conception, an undivided state existed in which the outer and the inner were not separated." The propensity to interact originates from the nature of emotions, of their mutuality (Endre K. Grandpierre, this volume) and field-nature, which is the basis of the well-known phenomenon of 'transference', the easy transfer of emotions in the trance-state from one person to another. This is the basis of the transference of emotions, its epidemic character, as well as the wide range phenomena of mass psychosis and collective impulses, when the individual consciousnesses merge into one single common consciousness (Wallon, ibid.).

\section{The Common Field of Consciousness}

Emile Durkheim (1899) showed the existence of collective psychical fields. He showed that the reality of the collective psychical fields is of the same degree as that of the physical fields, since it is measurable (through social indexes), and its relations and consequences show the same rate of stability. The collective psychical field generates a remarkably stable rate of suicides in a given nation. Individuals forming the society change from year to year, but the rate of suicides remains stable. This rate is different in different nations, and seems to be determined by moral factors. Moral life is per se a collective phenomenon, and the collective psychical field is an expression of the background moral fields of individuals. Our moral convictions are a certain kind of concerted brain activities, formed from our common characteristics. This is expressed also in the changes of the social indexes of e.g. suicide. Durkheim observed, that the activity of the society follows a seasonal rhythm, its intensity grows from January to July, and then decreases. Durkheim pointed out, that the suicidal index of the people living in marriage shows the same ratio to that of people of the same social class being widows, indifferently from the selected class. The simple reason for this is that the judgement of the society is of a general character, independent of the actual group of the society, although the social conditions of life sensitively change from group to group, therefore becoming widow would show a larger relative loss in the lower classes. Moral judgements are closely related to emotions, therefore we are led to the inference that common field of consciousness consists of emotions.

The rate of suicides is observed to grow with the age, and shows a tenfold increase from the young to old age. Accepting the plausible view that the social environment of the people does not show necessarily a more and more hostile 
face as they grow older, but remains more-or-less the same during a lifetime, we observe the existence of an effect independent from the immediate social environment. This effect is probably mostly of subjective character indicating the growing sensitivity of the people to the accumulating social influences. This effect lays an emphasis on the 'tuning' of individuals to the different influences, to the weakening of their 'psychic immune system' because of manipulation.

The 'everyday consciousness' of the people is the expression of useful informations, beliefs, habits and traditions. The basic behaviour, the modus vivendi and the actual activity is mostly determined also by the world-view of the person, which directs her/his system of values and conscious decisions. Determining factors of the world-view are the religious faith and the cohesion to the nation. Analysing these factors, we may observe that beliefs, habits, religions, traditions are related to the prehistory of the nation and mankind. The fundamental influence of the world-view to our activity is certainly explained by the still surviving factors of Nature and Cosmos within our psychic life. In this way, the everyday consciousness seems to be determined by the Universe, Mankind and nation - therefore, by the common fields of consciousness.

I know that emotions are a certain kind of taboo in the western civilisation. Emotions and thoughts should be separated forever - a principle almost generally accepted, in scientific circles as well. Nevertheless, thoughts are closely related to emotions, they may be regarded as the expression of them, as two stages of the same process. Our brain is made up as a community of $4 * 10^{10}$ neurones. From this enormous number of neurones, only ten-fifteen million is waiting for stimuli. The time-period of the building up and decay of the activation potential is around $10^{-3} \mathrm{~s}$. It means that our brain activates $10^{10}$ neurones in a second. This data is consequent with the data given above (Sect. V.) for the information processing speed of the whole brain in forms of neurones, $10^{10} \mathrm{bits} / \mathrm{s}$. Only a millionth or less is the speed of the conscious information processing, less than $10^{3} \mathrm{bits} / \mathrm{s}$. The process in which the 'unconscious' becomes 'conscious', is based on a certain selectivity, which may be paralleled with the process of the development of a conscious thought from an unconscious emotion. Blocking the emotions involves blocking the basis of consciousness, while keeping emotions does not lead necessarily to uncritical decision, since it is the normal way of the brain's activity to select the information by their content and choose which should be involved in aware consciousness. The large territories of unused neurones sign that our emotional world is poor as compared to its original capacity in a rate of 1/4 000 . There is not any other part of the body which would work with such a low efficiency. The electric work made by the heart, e.g., is 40-60 times of that of the brain's as a whole (Rein, G., 1995, personal communication), although it also participates in the general atrophy of the organism. It is important to note here, that the decrease of the basic level of the EM activity of the brain decrease of health of the whole organism (Oldfield, Coghill, 1988). The organ which is not used, dies. It is known in medicine that a whole range of illnesses is related to the 
anomalously low activity of brain, between cerebral innoculation and subsequent cellular malfunction of the body (Oldfield, Coghill, 1988). Psychosis, neurosis seems also to be related to undervitality of the brain. The brain's activity is largely parallel to the emotional intensity, when we feel that something important is happening to us. The brain may conquer back its lost territories, long-forgotten vast fields of untouched neurones, at a rate of 4000 times, and million times of that value, when the activity of the brain is at full speed. Compared to that state, our present use of the brain is something when we see through a small tube which shows one-millionth of the field of vision without the tube. Since the underutilisation of the brain leads to the self-destruction of the organism, psychic and somatic illnesses, emotions can not be exiled from the centre of the brain to its highly controlled peripheries. Elevation of the consciousness of mankind is unimaginable without the elevation of its basic level of activity, without a significant role of emotions.

After coining the term 'primary perception', I became aware of the same term already introduced into science. The phenomenon of 'primary perception' is known in child psychology (Pearce, 1977) denoting the extrasensory perception of children. Eloise Shields presents an evidence that telepathic ability peaks at age four, at which time their parents may begin to be aware of such activity (Peterson, 1974). The term 'primary perception' surfaces in electromagnetic context, as well, denoting the perceptions of plants through EM fields (Backster, 1968). Primary extrasensory perception was known in ancient cultures, such as 'seeing' (látás) in the magic world-experience of ancient Hungarians (Vekerdy, 1974).

The 'merged consciousness' within proper conditions, by the help of a careful attention, represents a higher expression of human existence, as in cases of entering a new era of mankind, like the origin of natural sciences at the Greeks or the renaissance, or at the formation and enlargement of collectives or groups. If we to develop a more evolved form of consciousness, we have to live with emotionally driven states of consciousness. The more the consciousness will be filled up with human, natural and cosmic motives, love, eagerness to act and desire to fulfil our destination, the more it will open up, and the more it will be active, powerful and intense. Consciousness when finding its natural field of action, its natural roots and natural harmony, is able to regain its cosmic power again.

It is important to point out that the suggested inductive model for the generation of consciousness offers a way for the 'freedom of thought'. The laws of the complete, original electromagnetism of Maxwell (1892) are richer and more correct than their simplified forms presented by Heaviside and Gibbs, known as Maxwell-equations, valid only within special conditions. Recently, Cornille (1995) pointed out that "the presence of the Ampere-force in the complete EM implies that a charged capacitor can accelerate its centre of mass without external help if it has an absolute motion with respect to ether." One can expect that spontaneous effects may be induced by the Lorentz force. I suggest 
that this spontaneity may be related to the observed spontaneous phenomena in the inorganic and organic world, especially in the collective fields of consciousness, where spontaneous induction may regularly occur.

\section{On the Destination of the Universe}

There are experiences for reaching the completion of our personal lives, for recognising our special talents and working on their developments. Nevertheless, when we reach a special emotional state, filled with galvanising powers, sometimes we experience a one-to-one correspondence to the genuine, original content of our personal life, when whole worlds being born inside us and getting flame with the lights of Eternity. Cosmic pathways open up in us only when our motivations are alive in a rate behind a certain threshold, and when a natural force develops them into a higher form of existence. Emotions are at the core of the existence, and behind their accepted role of colouring the fixed forms of reality, they have the power to shoot up the reality into a much more complete, fresh, nascent, creative and natural state. Emotions are creative, and creative imagination is the basic principle which forms and drives our lives, as well as the Universe as a whole (Petõcz, 1838; Froschammer, 1878). Emotions, like a field, have a nature to be shared by others, to extend to landscapes and enter into other consciousness. When emotions are alive and vital, they driving us to share them with the others. The material universe is only a skin of a much more alive, filled Universe, the body of which is constituted of emotions which are much more real than the known forms of reality. This reality is an intense, free, sparkling river of natural forces of emotions. We can conceive that the known material Universe is only a far side-descendant of the core Reality, of the real Universe, of which the fundamental nature is emotional, therefore much more free, inductive, selffulfilling and human. Losing this real Universe generates a schism and an emotional emptiness, and the void is filled - as history teaches us - with brutality, hate, power and destruction.

To illustrate the occasions of free emotional inspirations, I present here an example.

"Shortly before her $17^{\text {th }}$ birthday, Rosalyn Tureck was playing the Bach fugue in A minor from Book 1 of the Well-Tempered Clavier when she lost all awareness of her own existence. As she came to, she recalls, she saw Bach's music revealed in a completely new light, with a new structure that required the development of a novel piano technique. Over the next two days she worked out this technique on four lines of the fugue and then played it at her lesson. Her teacher told her it was marvellous, but impossible, that it couldn't be done.

"All I knew", says Tureck, "was that I had gone through a small door into an immense living, green universe, and the impossibility for me lay in returning through that door to the world I had known." 
Tureck went on to become a renowned concert artist, the first women invited to conduct the New York Philharmonic Orchestra and author of several books, including one in the works that links the structure of Bach's music to two physical theories." (S. Weisburg, 1987).

The experience of the deeper, alive Universe still survives on the rare occasions of the sparks of inspirations. Regarding the fact that social influences have a propensity to accumulate and amplify each other, high forms of states of consciousness, if widespread, could serve as a basis of a more human reality. If we have a realistic picture of the present, it helps in maintaining this reality, but the exploration of a deeper, more real reality is easily able to surface and resurrect when more and more people and collective shares the proper experiences and attitudes. When awakening the alive green universes within us, mankind may reach a stage in its evolution when above a critical threshold, these alive green universes become interactive, and begin to form a basis of a new type of reality, a much more human and much more conscious one.

\section{The Deformation of Consciousness in the Western Civilisation}

The well-known historian, Collingwood (1938) remarks, that "the art is the treatment of the community to the most horrible illness of the mind, the degeneration of consciousness". Tamas Vekerdy (1974) makes an attempt to solve the schism of our mind: "Consciousness, when turning against its roots, becomes an idol destructing and degenerating every life; but, when connected with the unconscious, becomes a vital factor. Intensifying consciousness may liberate almost the whole range of the unconscious". As Allport (1961) observed, "the self of the western people sticks out (from its inner world) as a thumb put up." The roots of this rectangular dysfunction go back to the absolutization of the self from the selves of the others, from the environment, Nature and the Universe. None can count as 'normal adult', or 'full-right warrior', if he/she does not accept the dogma of perfect alienation of men from each other.

Western culture, in aiming to domesticate consciousness, assumes the a priori degeneration of the human mind, which if undomesticated, shows an evil, rotten, natural born killer face. This way western culture degraded consciousness with a terror to a largely inert, practical, narrow-minded slave, full of fear (Endre $\mathrm{K}$. Grandpierre, this volume). This is why consciousness compensates itself also with his own terror and domination over every other factor of life, including the 'unconscious mind' and the other fellow people, generating hostility, criminality and down-to-hell thinking.

\section{Super-Organisms and Planetary Consciousness}


The evolution of consciousness is related to the social co-operation, to the collective consciousness. Collective consciousness itself may reach its completion through a co-operation supra-social. In this context, it is important to consider that the existence of super-colonies in Nature has been studied recently (Higashi, Yamauchi, 1979). They observed super-colonies of red Japanese ants Formica yessensis. Their super-colonies consists of 45000 colonies occupying 270 hectares, with 300 millions of workers and 1.1 million queens. These colonies are interconnected with a web of $100 \mathrm{~km}$ long paths. There is a permanent exchange of workers and queens between the groups. There is no aggression between the members of the super-colonies.

According to my theory outlined above, larger aggregates of individual units, when forming a group, with a global organisation background, may turn to be more sensitive to subtle outer, natural and cosmic influences. This result is consistent with the view of Goldberg, who points out that nations are not products of a lately evolution, but are primary facts of life. It is a universal, spiritual form of life to form a community (Hamvas, 1943). Interactions between the members of a healthy, well-organised society involve the possibility to easily reach information from all the members of the society. In optimal case, when the organisational activity of the society is well developed, all the information is processed and exchanged, shared and 'sacred' by sharing, therefore forming a Common Field of Consciousness of the society. Perceiving the nature of the Common Field of Consciousness of the society is a substantial part of a healthy society, as being a condition of the individual participation in the life functions of the society as a whole. Perceiving the natural and cosmic informations is again a substantial function, which is a condition of the harmonious relation of the society to its immediate and cosmic environment. The physical conditions to this refined sensing are given just by the cohered tuning and co-operation of individuals, acting as a larger whole, sensitive to radiation with larger wavelengths. Planetary consciousness may be approached when global-scale activity is in development. The presence of Schumann waves, and their direct interaction with the individual's brain activity give an additional, natural basis for the development of consciousness of mankind into a planetary consciousness.

\section{Healing of the Collective Consciousness Field of Mankind}

The formation of a group is not automatic at humans. Spontaneous targeting - e.g. when finding the proper members of a group to form - seems to be sporadic. The 'group' as a higher level entity is the envelop which keeps together the individuals. Until this envelope is not formed, one can find the peoples to be an aggregate and not in a group. But what is the nature of this 'envelop'? As Didier Anzieu expresses, the most important factors are the network of implicit and explicit rules, the established habits, the rites, the facts and actions with 
accepted values, which contribute to the formation of an inner space and a proper timeliness (Anzieu, 1984). I have to add as a substantial characteristic of any group a similar sensitivity, sharing some basic elevating or interest-expressing ideas, conceptions and motives to act, and propensity to similar emotional states and emotional drives. Being in a faceless mass, in an atomised society, in the absence of communities, without emotions to be shared, sooner or later will generate stress, anxiousness and tension, deforming the natural states of consciousness, degenerating our mind, which may enhance aggression and destruction. The formation of a real community, giving the frame to a meaningful life, is the task of the present societies.

To do this, it would be helpful to explore the physical conditions and physical forms of consciousness, and determine the proper conditions of the natural states of consciousness fields, therefore being able to create physical conditions which may generate favourable conditions to regain our physical and mental health. Learning that consciousness is basically an EM field (which is resonantly coupled to the vacuum field), and its sources are the cosmic systems of Sun, Earth and the Moon (Grandpierre, 1996d), together with the natural sources of the biosphere, especially the natural fields into which we can tune most easily, the physical field emitted by the human organisms, we may be able to measure and broadcast wave fields which heal the stress, intensify, galvanise, correcting the distortions of the natural fields, like stress and alienation, and then to broadcast fields which induce in us urge to participate in the collective forms of consciousness. Measuring the healing spectra of special sites like water-springs, nascent forests, solar and lunar oscillations of the earthly magnetosphere, we may be able to sample them and re-radiate them in forms of Schumann-waves.

Searching the conditions of the tuning of the individuals to the natural healing EM fields has the same importance as the possible explorations of changes in our EM environment, which do have a healing effect. Psychological research shows that the efficiency of tuning in between different people is determined largely by emotional connections, i.e. transpersonal connections are the most effective between lovers, parents and children, friends tuned to each other. This result suggests that mankind may heal itself if we are able to tune us more effectively to the natural sources of consciousness, to the natural powers living in us, revealing the natural beings behind the manipulated masks which are developed by an unnatural society's norms, and when our emotional bounds are strengthened towards the wider ranges of our personal existence, towards Nature and the Universe.

It is suggested that new types of mental techniques may be developed to explore the subjective effects of mental intensification (Grandpierre, 1995c). If Vekerdy (1974) is right and the cathartic effect of the theatre is based on the extrasensory transference of the emotions generated in the actors, we can imagine a theatre in which everybody participates simultaneously. The idea of the 'telepathic theatre' suggests a play in total darkness and silence. The actors play the real drama on stage, intensifying their emotions and consciousness, and the 
participants are measured simultaneously through EM detectors positioned in the performance hall. The facilitation effect of the large number of harmoniously tuned participants could be detected directly.

Moreover, in recognising the hidden social drives of human beings, we could mobilise these immense inner natural forces, and as a new form of art, we may invent socio-mental group therapy, when people meet and form a community to inspire each other not with de-intensifying meditation, but strengthening the opposite tendency, the vitality, flexibility, mental intensity and freshness. Certainly, the whole society could got a vital lightning by becoming aware of its real, socio-natural-cosmical nature.

Neural mind is connected to executive functions of bodily changes, an already fixed form of the mental processes. Consciousness, as understood by mainstream science, is an extremely small part of this executive neural mind. Our calculations and arguments strongly suggest, that consciousness may be and, by nature, has to be of a much wider range. Beside the quantitative intensification of the neural mind, we can develop and improve the quality of our brains' activity, spontaneity, tuning in to the much faster and subtler electronic, EM and quantumvacuum minds. Consciousness may regain its natural functions only when finding a partnership with his parental, subtler minds, with human communities, with Nature and the Universe. 


\section{References}

Adey, W. R. 1981, Tissue Interactions with Nonionizing Electromagnetic Fields, Physiological Reviews, 61, 435-514.

Albert, D. Z. and Vaidman, L. 1989, in Kafatos, M. (Ed.), On the Theory of the Collapse of the Wave Function, in "Bell's Theorem, Quantum Theory and Conceptions of the Universe", Kluwer, Dordrecht, 1-6.

Allport, G. W., 1961, Personality: Pattern and Growth in Personality, New York: Holt, Rinehart \&Winston, Chap. 6, p. 130.

Angyal, András, 1941, Foundations for a Science of Personality, The Commonwealth Fund, New York

Anzieu, D., 1984, Le Groupe et l'Inconscient. L'imaginaire groupal. Dunod.

Atkinson, R. L., Atkinson, R. C., Smith, E. E., Bem, D. J. (1993) Introduction to Psychology, $11^{\text {th }}$ ed., Harcourt Brace Jovanovich College Publishers, Forth Worth

Backster, Cleve, 1968, Evidence of Primary Perception in Plant Life, International Journal of Parapsychology, 10

Barrow, J. D. And Tipler, E. J. 1986, The Anthropological Cosmological Principle, Oxford, Oxford University Press.

Bartholomew, R. E. 1994, 'Tarantism, Dancing Mania and Demonopathy: the Anthro-Political Aspects of 'Mass-Psychogenic-Illness', Psychological Medicine, 24, 281-306.

Bauer, E. 1920, Die Grundprinzipien der rein naturwissenschaftlichen Biologie, Berlin.

Bauer, E. 1935, Theoretical Biology, Moscow-Leningrad, IEM, in Russian (1967, in Hungarian).

Bauer, E. and Borsdyko, S. 1936, Mutations and the Structure of Living Matter, Biodynamica, No. 14, 1-8.

Becker, R. O. and Selden, G. 1985, The Body Electric. Electromagnetism and the Foundation of Life. Quill, William Morrow, New York.

Bischof, M. 1995, Biophotonen. Licht in unseren Zellen. Einsenden an Zweitausendeins, Frankfurt

Bohm, D. in "Physics and the Ultimate Significance of Time", ed. by D. R. Griffin, State Univ. of New York Press, 1986, 183.

Breithaupt, H. 1989, Biological Rhythms and Communications, in Electromagnetic Bio-Information, eds. F.-A. Popp et al., $2^{\text {nd }}$ ed., Urban\&Schwarzenberg, 18-41

Burr, H. S. and Northrop, E. S. C. 1935, The Electrodynamic Theory of Life. Quart. Rev. Biol. 10, 322.

Burr, H. S. 1956, Effect of a Severe Storm on Electric Properties of a Tree and the Earth, Science 124, 1204-5.

Callender, A., Gilmanshin, R., Dyer, B., and Woodruff, W. 1994, Protein Physics, Physics World, August, 41.

Chen, S. C. 1937, Social Modification of the Activity of Ants in Nest-Building, 
Psychological Zoology, 10, 420-436

Clauss, G. and Hiebsch, H. 1961 Kynderpsychologie, 3e Auflage, Volk und

Wissen Volkseigener Verlag: Berlin

Collingwood, R. G. (1938) The Principles of Art. Oxford, Clarendon Press, 1938 ,

p. 336

Cornille, P. 1995, The Lorentz Force and Newton's Third Principle, Canadian Journal of Physics, 73, 619-625.

Cox, A. N. and Giuli, 1968, Principles of Stellar Structure

Crick, F. H. C. 1994, The Astonishing Hypothesis-The Scientific Search for the Soul. Simon and Schuster, London.

Dashiell, J. F., 1930, An Experimental Analysis of Some Group Effects, Journal of Abnormal and Social Psychology, 25, 190-199

Drischel, H. 1972, Einfuhrung in die Biokybernetik. Akademie-Verlag, Berlin, 1972, 26, Abb. 6.

Durkheim, E. 1899/1960, Le Suicide, Presse Universitaire de France, Paris

Eccles, J. C. 1986, Do Mental Events Cause Neural Events Analoguosly to the Probability Fields of Quantum Mechanics? Proc. Roy. Soc. London, B227, 411-428.

Eccles, J. C. 1994, How the Self Controls its Brain, Springer-Verlag, Berlin Elsasser, W. M. 1958, The Physical Foundation of Biology. An Analytical Study.

Pergamon Press, Oxford.

Fábián, Gyula, 1975/1989, in The Foundations of Life, ed. Imre Törõ, Gondolat, Budapest, Chap. 10.

Farkaslaki Hints, Elek (1939) Medieval Medicine (in Hungarian), Budapest, 130

Feynman, R. P., Leighton, R. B., Sands, M., 1963, The Feynman Lectures on Physics

Figar, Stefan 1959, The Applications of Pletysmography to the Objective Study of so-called Extrasensory Perception. Journal of the Society for Psychical research, 40, No. 72, 162

Froschammer, J. 1877, Die Phantasie als Grundprinzip des Weltprocesses, München, Theodor Ackermann

Grandpierre, A. 1988, The Possibilities of the Self in the Present Culture, Forrás 1988/2, in Hungarian

Grandpierre, A. 1991, Our Cosmic Drive: The World-Instinct, Harmadik Szem, October (in Hungarian)

Grandpierre, A. 1992, Cosmic Tuning. Harmadik Szem, \#13 (in Hungarian)

Grandpierre, A. 1995a, Peak Experiences and the Natural Universe, World Futures, 44, 1-13

Grandpierre, A. 1995b, Quantum-Vacuum Interactions in the Brain, in the 
Appendix of The Interconnected Universe. Conceptual Foundations of Transdisciplinary Unified Theory, by Ervin Laszlo, World Scientific, Singapore, 113-117.

Grandpierre, A. 1995c, The Telepathic Theatre. Harmadik Szem, No. 51 (in Hungarian)

Grandpierre, A. 1996a, A Pulsating-Ejecting Solar Core Model and the Solar

Neutrino problem, Astronomy and Astrophysics, in press

Grandpierre, 1996b, The Sun as an Extremely Sensitively Coupled and

Regulated System, conference proceedings of the meeting of the Club of

Budapest at the Khepri Institute (in Italian)

Grandpierre, A. 1996c, Organic Phenomena in the Cosmos, ibid.

Grandpierre, A. 1996d, Cosmic Influences on Living Matter, Harmadik Szem,

Nos. 55 and 56 (in Hungarian)

Grandpierre, E. K. 1996, Cosmic Systems of Consciousness, Their Development,

Two Principal Branches and Evolution from the Golden Age until the

Present, conference proceedings of the meeting of the Club of Budapest at the Khepri Institute (in Italian).

Gu, Q. and Rauch, A. 1994, talk given in the Internat. A. G. Gurwitsch Conf.,

Moscow, Sept. 28.-Oct. 4. Non-Equilibrium and Coherent Systems in Biophysics, Biology and Biotechnology.

Gurwitsch, A. 1922, Über den Begriff des Embryonalen Feldes, Archiv für

Entwicklungsmechanik, 51, 383-415

Hemley, R. J. 1995, Turning off the Water, Nature 378, 14

Hess, B. and Mikhailov, A. 1995, Microscopic Self-Organization in Living

Cells: A Study of Time Matching, Journal of Theoretical Biology, 176, 181-184

Higashi, S. and Yamauchi, K., 1979, Influence of a Supercolonial Ant Formica (Formica) yessensis Forel on the Distribution of Other Ants in Ishikari Coast, Japanese Journal of Ecology, No. 29, 257-264

Hamvas, B. 1943/1995, Scientia sacra, Medio Kiadó, Budapest, Vol. II., p. 344 (in Hungarian)

Jaisson, P., 1993, La fourmi et le sociobiologiste, Editions Odile Jacob Károlyházy, F. 1966, Nuovo Cimento 42A, 390-402.

Károlyházi, F. 1974, Gravitation and Quantum Mechanics of Macroscopic Bodies, Magyar Fizikai Folyóirat, Vol. XXII, 23-85 (in Hungarian)

Koltsov, H. K. 1936, Organisation of cells. Biomedgizh, Moskva-leningrad Kotov, V. A.,1985, On the 160-minute Solar Oscillations, Solar Physics, 100, 101

Kotov, V. A. 1995, From solar oscillations to restrictions on the standard cosmology, in "4th SOHO Workshop: Helioseismology"

König, H. L., 1989, Bioinformation - Electrophysical Aspects, in Electromagnetic

Bio-Information, eds. F.-A. Popp et al., $2^{\text {nd }}$ ed., Urban\&Schwarzenberg, $42-73$ 
König, H. L. and Angermüller, F. 1960, Einfluß niederfrequenter elektrischer Vorgange in der Atmosphare. Die Naturwissenschaft, 47, 485-490

Kuznetsov, A. E., 1992, Synchronization of Biosynthesis Activity of Microbial Producers Under Cosmogeophysical Rhythms, Biofizika, 37 (4), 772-784 (in Russian).

Ladik, J. J. 1987, Intern. J. Quantum Chemistry: Quantum Biology Symposium 14,3 .

Laszlo, E. 1993, The Creative Cosmos, Floris Books, London.

Laszlo, E. 1995, The Interconnected Universe. Conceptual Foundations of Transdisciplinary Unified Theory. World Scientific

Loubeyre, P. and LeToullec, R. 1995, Stability of $\mathrm{O}^{2} / \mathrm{H}^{2}$ mixtures at high pressure, Nature 378, 44

Ludwig, W. 1974, Electric and Magnetic Field Strengths in the Open and in Shielded Rooms in the ULF-to LF-zone, in ELF and VLF Electromagnetic Field Effects, ed. M. A. Persinger, 35-80.

Maxwell, J. C. 1892, A Treatise on Electricity and Magnetism, $3^{\text {rd }}$ ed., Oxford, Clarendon Press

Merkulov, O. P. 1978, The Wonders of Magnetism, Technika, Kiev (in Ukrainian; 1986, in Hungarian)

Mikhailov, A. and Hess, B. 1995, Fluctuation in Living Cells and Intercellular Traffic, Journal of Theoretical Biology, 176, 185-192

Miller, D. L. (1985) Introduction to Collective Behavior. Wadsworth,: Belmont, CA.

Newton, T. D. and Wigner, E. P. 1949, Rev. Mod. Phys. 21, 400

Oldfield, H. and Coghill, R. 1988, The Dark Side of the Brain. Major Discoveries in the Use of Kirlian Photography and Electrocrystal Therapy, Element Books, Shaftesbury

Pearle, P. and Squires, E. 1994, Phys. Rev. Lett. 73, 1

Pearce, J. C. 1977, Magical Child, A Plume Book

Peterson, J. 1974, Some Profiles of Non-Ordinary Perception in Children. Seminar Study for the Degree of Master of Arts. Univ. Of California, Berkeley

Petöcz, M. 1838, Ansicht der Welt. Ein Versuch die Höchte aufgabe der Philosophie zu lösen. Leipzig, F. A. Brodhaus

Popp, F. A., Li, K. H., and Gu, Q. 1992, Recent Advances in Biophoton Research and Its Applications, World Scientific.

Popp, F.-A., 1994, Modern Physical Aspects of Mitogenetic Radiation (Biophotons), lecture presented at the Intern. A. G. Gurwitsch Conf., Moscow

Ravitz, L. J. 1962, History, Measurement, and Applicability of Periodic Changes in the Electromagnetic Field in Health and Disease, Annals New York Academy of Sciences, 98, 1144-1201

Richardson, Janet, 1995, Toddler Perception and Ritualization of NOR 
Phenomena: A Qualitative Study in Rational and Pure Cognitive Modes, paper presented at the annual meeting of the Society for Anthropology of Consciousness, San Francisco, April 1995

Rose, S. 1973, The Conscious Brain, Weidenfeld and Nicholson.

Ruth, B. 1989, in Electromagnetic Bio-Information, eds. F.-A. Popp et al., $2^{\text {nd }}$ Edition, Urban and Schwarzenberg, 128-143.

Scheffer. L. K. 1994, Quart. J. Roy. Astr. Soc. 35, 157-175.

Schumann, W. O., König, H. L., 1954, Atmospherics geringster Frequenzen. Naturwissenschaften, 41, 183-184.

Scott, B. I. H. 1963, Feedback-Induced Oscillations of Five-Minute Period in the Electric Field of the Bean Root, Annals of the New York Acad. of Sci. 98, 890-900

Sheldrake, R. 1981, A New Science of Life, Blond and Briggs Ltd, London Sheldrake, R. 1988, The Presence of the Past. Morphic Resonance and the Habits of Nature, Vintage Press, London

Silbernagl, S. and Despopoulos, A. 1991, Taschenatlas der Physiologie, Georg Thieme-Verlag, 1991, p. 287.

Smelser, N. J. (1962) Theory of Collective Behavior, Prentice-Hall, New Jersey. Smith, C. W. and Best, S. 1989, Electromagnetic Man, The Bath Press, London Smith, C. W. 1995, Measurements of the Electro-Magnetic Fields Generated by Biological Systems, in "Biophysical Aspects of Coherence, Neural Network World", Conference 1995 - Special Issue, ed. M. Novák, International Journal on Neural and Mass-Parallel Computing and Information Systems, 5, No. 5, 819-830

Spemann, H. C. 1938, Embryonic Development and Induction, New Haven, Yale

University Press

Szent-Györgyi, A. 1960, Introduction to a Submolecular Biology. Acad. Press, New York - London.

Szent-Györgyi, A. 1968, Bioelectronics. Science, 161, 988-990.

Szent-Györgyi, A. 1974, lecture presented at the Eötvös Lóránd University, Budapest

Tart, C. T. 1969, Psychedelic Experiences Associated with a Novel Hypnotic

Procedure, Mutual Hypnosis, in Altered States of Consciousness, ed. C.

T. Tart, New York, John Wiley and Sons, 291-308

Tepperwein, K., 1977, Die Hohe-Schule der Hypnose, Ariston Verlag, Geneve, p. 112

Thomas, L. 1974, The Lives of a Cell. Notes of a Biology Watcher. Bantam Books, Toronto

Triplett, N. (1898) The Dynamogenetic Factors in Pacemaking and Competition,

Amer. J. Psychol. 9, 507-533

Turner, R. H. and Killian, L. M. (1972) Collective Behavior ( $2^{\text {nd }}$ ed.), Prentice Hall:Englewood Cliffs, NJ. 
Vekerdy, Tamás, 1974, "Tools of the Effect of Theatre - by the Teaching of Master Zeami. Psychological Analysis." Magvetõ Kiadó, Budapest, in Hungarian.

Völgyesi, Ferenc, 1962, Medical Hypnosis, Medicina, Budapest, 71 ) in Hungarian).

Wallon, H. 1959, La role de l'autre dans la conscience du moi. Enfance, No. 3 4, 87-97.

Weisburg, S. 1987, The Spark. Personal testimonies of Creativity. Science News 132, 298-300

Weiss, P. 1939, Principles of development. New York, Holt.

Woody, C. D. 1982, Memory, Learning, and Higher Function. A Cellular

View. Springer-Verlag, New York. 